\title{
Comments on "Thermodynamics of cis,cis-muconic acid solubility in various polar solvents at low temperature range"
}

\author{
Jack M. Carraher,, a,b John E. Matthiesen,, ${ }^{a, b}$ Jean-Philippe Tessonnier ${ }^{a, b, *}$ \\ a Department of Chemical and Biological Engineering, lowa State University, Ames, lowa, \\ United States \\ ${ }^{\mathrm{b}}$ NSF Engineering Research Center for Biorenewable Chemicals (CBiRC), Ames, lowa, United \\ States
}

*Corresponding author. Email: tesso@iastate.edu Phone: +1 515-294-4595

\begin{abstract}
New light is shed on results published by Scelfo, Pirone, and Russo in "Thermodynamics of cis,cis-muconic acid solubility in various polar solvents at low temperature range". We show that under the conditions described in their article, cis,cis-muconic acid isomerizes to cis, transmuconic acid within minutes. This isomerization can be easily overlooked as both isomers present similar retention times during liquid chromatography analysis. Yet, the consequences are significant as the cis,trans isomer is five times more soluble at room temperature under acidic conditions than cis, cis-muconic acid. $\mathrm{pH}$ should also be measured and taken into account as this parameter dramatically influences the species in solution, hence the solubility limit.
\end{abstract}

KEYWORDS: cis,cis-Muconic acid; cis,trans-Muconic acid; Isomerization; Solubility; Aqueous solution; $\mathrm{pH}$

\section{INTRODUCTION}

Muconic acid (MA) has recently emerged as a promising biobased intermediate for the sustainable production of adipic acid, terephthalic acid, and other monomers central to the production of various commodity polyamides and polyesters such as Nylon 6,6 and polyethylene terephthalate (PET), an estimated market value of 118 billion U.S. dollars per year.[1, 2] MA is currently gathering significant interests from both industry [3-5] and academic research groups worldwide [6-8]. Substantial progress has already been achieved to produce MA from plant-based biomass by fermentation using metabolically engineered yeasts and bacteria. The designed microbes were shown to convert cellulosic sugars and lignin monomers to cis,cis-muconic acid (ccMA) with high yield and titer. Further conversion of the ccMA intermediate to the desired renewable diacid monomer is performed through chemical reactions, typically in the presence of a heterogeneous catalyst [8-17].

Advancements in downstream chemical conversion of MA to adipic, terephthalic, and other diacids are also conditioned by the development of a fundamental understanding of the MA 
chemistry and an accurate determination of its physicochemical properties. It is therefore crucial that data published on this key intermediate is based on appropriately validated experimental and analytical techniques. We address here several errors related to the experimental and analytical methods that have been published by Scelfo et al. which, unfortunately, significantly impact their solubility results [18].

\section{RESULTS AND DISCUSSION}

MA is a six carbon atom diunsaturated dicarboxylic acid structurally similar to adipic acid. However, muconic acid exists in three different isomers depending on the configuration of its carbon-carbon double bonds: cis,cis-, cis,trans-, and trans, trans-muconic acid (respectively ccMA, ctMA, and ttMA). These isomers have vastly different solubility at low $\mathrm{pH}$ at which they are fully protonated (ccMA $\sim 1 \mathrm{~g} / \mathrm{L}$, ctMA $=5.2 \mathrm{~g} / \mathrm{L}$, and ttMA $=90 \mathrm{mg} / \mathrm{L}$ ) [14]. The three isomers are easily distinguished by ${ }^{1} \mathrm{H}$ nuclear magnetic resonance (NMR) and representative ${ }^{1} \mathrm{H} N M R$ spectra of a ccMA and ctMA mixture are shown in Figure 1a. However, their separation and quantification using high pressure liquid chromatography (HPLC) is delicate. We believe that the HPLC method and column selected by Scelfo et al. could be insufficient for separating ccMA from ctMA and could yield flawed solubility data. Our HPLC analysis using an Aminex HPX-87H column (BioRad) at $30{ }^{\circ} \mathrm{C}$ with a $0.30 \mathrm{~mL} / \mathrm{min}$ flow rate of $5 \mathrm{mM} \mathrm{H}_{2} \mathrm{SO}_{4}$ indicates that the isomers cannot be separated with this setup (Figure $1 \mathrm{~b}$ ). The Aminex HPX-87H column is very similar to the column used by the authors (REZEX ROH+ organic acid) and we suspect that it is equally unsuitable for cc- and ctMA separation, particularly at $70{ }^{\circ} \mathrm{C}$ with a flow rate of 0.6 $\mathrm{mL} / \mathrm{min}$ described in their article. It is, therefore, understandable that the authors assumed that they were observing only ccMA.
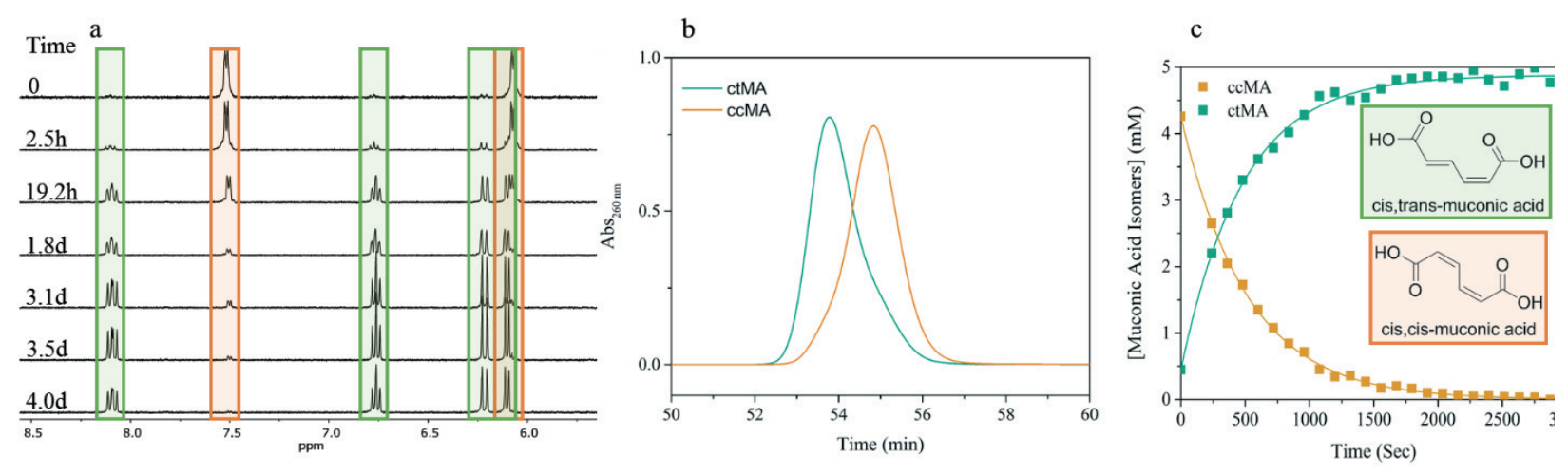

Figure 1. a) ${ }^{1} \mathrm{H}$ NMR spectra of ccMA (orange) conversion to ctMA (green) at $22.5{ }^{\circ} \mathrm{C}$ as a function of time. b) HPLC chromatograms of genuine ccMA and ctMA acquired on a Waters e2695 HPLC equipped with a photodiode array detector. The conditions were the following: Aminex HPX-87H column (BioRad), $0.30 \mathrm{~mL} / \mathrm{min} 5 \mathrm{mM} \mathrm{H}_{2} \mathrm{SO}_{4}$, column temperature $30{ }^{\circ} \mathrm{C}$. c) Kinetic trace of ccMA conversion to ctMA at $83^{\circ} \mathrm{C}(\mathrm{pH} \sim 3.5)$.

With the three isomers in mind, one must consider transformations and potential equilibria between them and how conditions will affect not only the thermodynamics but also the kinetics. 
The specific kinetic data has not yet been published. However, the literature reports that isomerization of the cc- isomer to the ct- isomer occurs readily (in as little as 10 minutes under reflux) $[10,19]$. We reported a half-life for this isomerization of less than 1 day at room temperature [14]. This means that within the 4.5 hours that ccMA was 'allowed to equilibrate' in Scelfo et al.'s study, nearly $13 \%$ would have been converted to ctMA. Our current work, which has not yet been submitted for publication, shows that even at temperatures as low as $30{ }^{\circ} \mathrm{C}$ the half-life of $\mathrm{ccMA}^{-}$(singly deprotonated ccMA) is only 137 minutes and 816 minutes for ccMA. The isomerization is significantly faster at $75^{\circ} \mathrm{C}\left(\mathrm{t}_{1 / 2} \sim 1\right.$ minute and 17 minutes for ccMA and ccMA, respectively). A kinetic trace of ccMA conversion $\left(83^{\circ} \mathrm{C}\right.$ at $\left.\mathrm{pH} \sim 3.5\right)$ is shown in Figure 1c. At this $\mathrm{pH}$, a mixture of $\mathrm{ccMA}, \mathrm{ccMA}^{-}$and $\mathrm{ccMA}^{2-}$ (fully deprotonated ccMA) is present. $\mathrm{ccMA}^{2-}$ is stable at all temperatures. We do not fault the authors for not knowing the specific rate constants as they have not been made public. However, the authors cite several works in which the ready isomerization to ctMA is mentioned and yet they did not take this transformation into consideration during experimental design.

Finally, the solubility of any acid most certainly is dependent upon the $\mathrm{pH}$ of the solution; the protonation state has a significant effect on the solubility due to differences in the molecule's charge and interactions with the solvent. For instance, we have observed that ctMA exhibits a solubility of $5.2 \mathrm{~g} / \mathrm{L}$ at $\mathrm{pH}<2$ while $\mathrm{ctMA}^{2-}(\mathrm{pH}>6.5)$ presents a solubility of more than $100 \mathrm{~g} / \mathrm{L}$ [20]. Likewise, at low $\mathrm{pH}$ the solubility of ccMA was found to be $\sim 1 \mathrm{~g} / \mathrm{L}$ while Drath's was able to obtain titers as high as $59.2 \mathrm{~g} / \mathrm{L} \mathrm{CCMA}^{2-}$ at elevated $\mathrm{pH}$ [16].

All of the above arguments hold true in other solvents with the exception of $\mathrm{pH}$ effects. Our ${ }^{1} \mathrm{H}$ NMR work indicates that fully protonated MA is the most prevalent form in other solvents.

We value the efforts of the authors to contribute important fundamental data on MA. It is clear that MA is a much more complicated molecule than its analog adipic acid and, therefore, these studies require more intense scrutiny and additional considerations relative to those of adipic acid. To aid in future product analysis, we have detailed a procedure to quantify the three isomers of MA with baseline separation as shown in Fig S1a within the reference [14]. This method is explicitly detailed in Table 1.

Table 1. Liquid chromatography method to separate MA isomers

\begin{tabular}{cc}
\hline Instrument & Water Acquity H-Class UPLC \\
Column & Waters HSS C18 $(1.8 \mu \mathrm{m}, 2.1 \times 100 \mathrm{~mm})$ \\
& $0.2 \%$ Formic Acid/Water $(95 \%)$, Methanol \\
Isocratic Mobile Phase & $(5 \%)$ \\
Flow Rate & $0.45 \mathrm{ml} \mathrm{min}{ }^{-1}$ \\
Column Temperature & $45^{\circ} \mathrm{C}$ \\
Injection Volume & $8 \mu \mathrm{l}$ \\
Detector & Waters Acquity PDA Detector set at $230 \mathrm{~nm}$ \\
\hline
\end{tabular}

As a general strategy for separation, in particular for reverse phase chromatography, an acidic buffer is required for MA retention and subsequent separation to occur. As a rule of thumb, the higher the organic content of the mobile phase the faster the elution time. While the separation of isomers presents some difficulty, the molar absorptivity for this compound is large making UV detection very sensitive. RI is also suited for this application, but with less sensitivity. 
It should also be noted that this is one outlined procedure and we anticipate that the three MA isomers could also be separated with ion exclusion and normal phase chromatography under the right conditions. Due to the increasing popularity of this molecule, as the authors point out, each method could likely have its own benefits and disadvantages in the near future.

\section{ACKNOWLEDGEMENT}

Part of this material is based upon work supported in part by the National Science Foundation Grant Numbers CBET-1512126 and EEC-0813570.

\section{REFERENCES}

[1] Polyamide Market by Type (PA 6, PA 66, Bio-Based \& Specialty), by Application (Automotive, Films \& Coatings, Industrial/Machineries, Consumer Goods \& Appliances, Fibers \& Textiles, and Others), by Process, and by Region - Global Trends and Forecast to 2020, 2015.

[2] J. John, Global Polyester Fiber Market Value Share, Supply Demand, Share and Value Chain 2014-2020, OpenPR homepage, 2016.

[3] DEINOVE SA. Home Page. http://www.deinove.com/ (accessed June 2016), www.deinove.com, 2015.

[4] Myriant Corp., Home Page. http://www.myriant.com/ (accessed June 1, 2016).

[5] Santa Cruz Biotechnology Inc., Home Page. www.scbt.com (accessed June 1, 2016).

[6] N. Yoshikawa, S. Mizuno, K. Ohta, M. Suzuki, Biotechnology in JapanMicrobial production of cis,cis-muconic acid, Journal of Biotechnology, 14 (1990) 203-210.

[7] J.H. Hsieh, S.J. Barer, P.C. Maxwell, Muconic acid productivity by a stabilized mutant microorganism population, Calanese Corporation, USA, 1985.

[8] D.R. Vardon, M.A. Franden, C.W. Johnson, E.M. Karp, M.T. Guarnieri, J.G. Linger, M.J. Salm, T.J. Strathmann, G.T. Beckham, Adipic acid production from lignin, Energy \& Environmental Science, 8 (2015) 617-628.

[9] J.W. Frost, K.M. Draths, Synthesis of adipic acid from biomass-derived carbon sources, Purdue Research Foundation, 1996.

[10] J.W. Frost, A. Miermont, D. Schweitzer, V. Bui, Preparation of Trans, Trans Muconic Acid and Trans, Trans Muconates, Amyris, Inc., 2013.

[11] J.W. Frost, A. Miermont, D. Schweitzer, V. Bui, E. Paschke, D.A. Wicks, Biobased polyesters, Draths Corporation, 2013.

[12] J.W. Frost, A. Miermont, D. Schweitzer, V. Bui, D.A. Wicks, Terephthalic and trimellitic based acids and carboxylate derivatives thereof, Amyris, Inc., 2013.

[13] J.W. Frost, A. Miermont, D. Schweitzer, V. Bui, D.A. Wicks, Cyclohexane 1,4 carboxylates, Amyris, Inc., 2013.

[14] J.E. Matthiesen, J.M. Carraher, M. Vasiliu, D.A. Dixon, J.-P. Tessonnier, Electrochemical Conversion of Muconic Acid to Biobased Diacid Monomers, ACS Sustainable Chemistry \& Engineering, 4 (2016) 3575-3585.

[15] M. Suastegui, J.E. Matthiesen, J.M. Carraher, N. Hernandez, E.W. Cochran, Z. Shao, J.-P. Tessonnier, Integrating Metabolic Engineering and Electrocatalysis for the Production of Biobased Polyamides from Sugar, DOI (2015).

[16] V. Bui, M.K. Lau, D. Macrae, D. Schweitzer, Methods for Producing Isomers of Muconic Acid and Muconate Salts, Amyris, Inc., USA, 2012.

[17] E. Paschke, Biobased polyamides, Amyris, Inc., 2012.

[18] S. Scelfo, R. Pirone, N. Russo, Thermodynamics of cis,cis-muconic acid solubility in various polar solvents at low temperature range, Journal of Molecular Liquids, 222 (2016) 823-827. 
[19] J.W. Frost, K.M. Draths, Bacterial cell tranformants for production of cis, cis-muconic acid and catechol, Purdue Research Founation, 1997. 